\title{
Norms Governing the Dialect Translation of Charles Dickens' Great Expectations: An English-Greek Perspective
}

\author{
Despoina Panou ${ }^{1}$ \\ ${ }^{1}$ Department of Foreign Languages, Translation and Interpreting, Ionian University, Greece \\ Correspondence: Despoina Panou, Department of Foreign Languages, Translation and Interpreting, Ionian \\ University, Greece. E-mail: panoudespoina@gmail.com
}

Received: March 11, 2018; Accepted: March 28, 2018; Published: April 16, 2018

\begin{abstract}
This paper aims to investigate the norms governing the translation of fiction from English into Greek by critically examining two Greek translations of Charles Dickens' novel Great Expectations. One is by Pavlina Pampoudi (Patakis, 2016) and the other, is by Thanasis Zavalos (Minoas, 2017). Particular attention is paid to dialect translation and special emphasis is placed on the language used by one of the novel's prominent characters, namely, Abel Magwitch. In particular, twenty instances of Abel Magwitch's dialect are chosen in an effort to provide an in-depth analysis of the dialect-translation strategies employed as well as possible reasons governing such choices. It is argued that both translators favour standardisation in their target texts, thus eliminating any language variants present in the source text. The conclusion argues that societal factors as well as the commissioning policies of publishing houses influence to a great extent the translators' behaviour, and consequently, the dialect-translation strategies adopted. Hence, greater emphasis on the extra-linguistic, sociological context is necessary for a thorough consideration of the complexities of English-Greek dialect translation of fiction.
\end{abstract}

Keywords: Great Expectations, Norms, Dialect-Translation, English-Greek, Translation-Strategies, Publishing Houses

\section{Setting the Scene: Norms in Translation Studies}

The descriptive approach to translation studies began to evolve in the second half of the $20^{\text {th }}$ century. Moving away from prescriptivism, descriptive theories of translation try to describe what translations are like or could be like. In particular, drawing from the work of Russian formalists of the 1920s, the Israeli scholar Itamar Even-Zohar developed his polysystem theory which viewed translated literature - an area which has often been neglected in literary theory - as a system functioning in the wider socio-historical and literary systems of the target culture. In fact, the polysystem theory developed from Even-Zohar's need to solve certain translation issues with Hebrew literature.

In more detail, the key concept of his theory is the term system, even though it could be argued that "the terms system and polysystem are to a large extent synonymous" (cited in Shuttleworth, 1998:176). According to Even-Zohar, polysystem is an umbrella term encompassing all the systems and it is defined by Shuttleworth and Cowie (1997) as follows:

The polysystem is conceived as a heterogeneous, hierarchised conglomerate (or system) of systems which interact to bring about an ongoing, dynamic process of evolution within the polysystem as a whole.

(Shuttleworth and Cowie, 1997:176)

It should be mentioned that the positioning of systems is not static but that they continuously interact and compete with one other. For instance, if conservative literary types are the most influential, then the more innovative ones will be found in the lower systems and vice versa. Because of this constant tension that exists, the position of translated literature is also changing, occupying either a primary or a secondary position in the polysystem. When primary, "it participates actively in shaping the centre of the polysystem" (Even-Zohar, 1978/2000:193). This can happen when the following three sets of circumstances take place: Firstly, when an emergent form of literature has not been established, it is only natural to look back to older literary, ready-made models. Secondly, it could be the case that the original literature of the particular system may be 'peripheral' or 'weak'. Hence, the literature of a small nation is overpowered by that of a larger one. Thirdly, in moments of crisis at which already established 
models are considered insufficient, then the vacuum can be comfortably filled by translated literature. Consequently, what method of translation is used is determined by the position the translated literature holds within the polysystem. According to Even-Zohar (1990:51), "translation is no longer a phenomenon whose nature and borders are given once and for all, but an activity dependent on the relations within a certain cultural system".

This non-prescriptive approach enables translators to examine the translation process within a wider context, acknowledging the fact that the translated text is autonomous; existing in its own right. In other words, the target text is shaped by systemic constraints which are not only concerned with textual considerations but primarily take into account the way the translation functions in the target cultural and literary systems.

Even-Zohar's target-oriented approach was significantly extended by Gideon Toury, who was working with him in Tel Aviv. More specifically, Gideon Toury introduced the concept of norms in translation behaviour which are defined as follows:

the translation of general values or ideas shaped by a community - as to what is right or wrong, adequate or inadequate - into performance instructions appropriate for and applicable to particular situations.

(Toury, 1995:55)

Norms refer to the factors and sociocultural constraints that influence the translation process and serve as a descriptive tool for analysing types of translation behaviour. In particular, Toury (1980:53-57, 1995:56-61) distinguishes three types of translational norms: initial norms, preliminary norms and operational norms. The initial norm in translation involves the basic choice of adhering either to the norms of the source text (henceforth ST) or of the target text (henceforth TT). According to Baker (1998:164) a translation's adequacy with respect to the source text is determined by adherence to source norms whereas "adherence to norms originating in the target culture determines its acceptability within that culture. Preliminary norms are subdivided into translation policy and directness of translation, the former referring to factors determining the choice of source-text types and the latter relating to "a society's tolerance or intolerance towards a translation based on a text in an intermediate language rather than on the source language text" (cited in Baker, 1998:164). Lastly, operational norms refer to the decisions made during the translation process. Toury distinguishes between two types of operational norms: (a) matricial norms, which mainly deal with issues such as the distribution of textual material and textual segmentation, and (b) textual-linguistic norms, which dictate the selection of TT linguistic material in the formulation of the TT.

In addition, Toury emphasises that "it is norms that determine the (type and extent) of equivalence" in a given translation since it is through norms that we get to investigate possible "patterns" or "regularities" of translational behaviours. In this respect, Pym (2010) describes Toury's approach to translation as follows:

For Toury, the study of numerous translations reveals that translators behave differently in different cultures and historical settings, and their behaviours may be patterned. Those patterns form norms if and when there is some kind of sanction for noncompliance.

(Pym, 2010:6)

Thus, for Toury the primary aim of the descriptive translation studies is to subject to critical scrutiny the models of both the source system and the target system and critically evaluate the cultural product that emerges from the dialectical relationship between texts, cultures, institutions and human agents.

It could be claimed that the concept of norms has given a new impetus to the field of translation studies, in the sense that it has replaced the old, problematic concept of equivalence and has introduced the autonomy of the TT, which functions within a particular literary system dialectically with others rather than individually. Nevertheless, such an approach is not infallible. In particular, Lefevere (1983:194) has questioned the need for the primary/secondary distinction and Gentzler (2001:121-123) has pointed out that the polysystem theory has been very much influenced by Russian formalism, which was a model dating from the 1920s, and it is doubtful whether it is appropriate for translated texts created in the 1970s. Hence, the objectivity of the model is questioned on the basis that it lacks focus on the real-life constraints placed on texts and translators. Finally, Hermans (1995:218) has criticised Toury's target-oriented approach by claiming that he is so centred on the TT and target culture that he overlooks the status of the ST in its own culture.

Despite the above criticisms, Toury's introduction of norms governing the translator's behaviour is acknowledged for having moved translation studies away from its obsession with equivalence, and introducing the investigation of translated literature within the wider historical and literary systems of the target culture. Descriptive translation 
studies refuse to make a priori statements about what translation is or should be and instead, extend their areas of research to investigate all the conditions which operate in a specific culture at a given point in time. Perhaps, one of the biggest contributions of Toury's norms is the significant role his theory has played in revealing the diversity and multiplicity of translation practices in different historical periods and in different cultures. Hence, it will form the backbone of this research paper.

\section{Charles Dickens' Great Expectations and its Translations into Greek}

The aim of the present paper is to investigate the translational norms from English into Greek in the genre of fiction. This present case study will focus on two Greek translations of Charles Dickens' Great Expectations, having as a primary aim the identifications of patterns and norms in dialect translation of Dickens' Great Expectations. This novel was chosen because it enjoys worldwide reputation and it is one of the most translated. Before juxtaposing the ST with the TTs, it is of immense importance to provide some background information as to the nature and character of this work of fiction. First published in weekly installments over a 9-month period, in Dickens' own periodical, All the Year Round from 1st December 1860 to August 1861, Dickens' Great Expectations consists of three volumes describing three stages in the protagonist's life. More specifically, chapters one to nineteen, portray Pip's first stage of development; chapters twenty to thirty-nine describe his second stage of development, whereas chapters forty to fifty-nine depict the last stage. The main theme running throughout this novel, which after its serialisation, enjoyed immediate success, is the bildungsroman of its main protagonist, Pip. In other words, this novel is about the metamorphosis of Pip from an innocent immature boy to a fully-grown man who has come to terms with his "expectations", thus re-evaluating his desires and values.

As the novel's title implies, money is another important theme in Great Expectations, wealth being inextricably linked to social status in nineteenth-century Victorian society. This differentiation of social classes is linguistically manifested by the employment of various linguistic techniques by the author such as "misspelling a word, to represent the different sound of an individual who came from a different class" (Li, 2014:11). The language of the protagonist himself, as a child and as a grown-up, evolves as he matures. The language of Abel Magwitch, the escaped criminal and Joe Gargery, the blacksmith, is indicative of their lower working class status, whereas Miss Havisham's and Estella's middle class Standard English, reveals their upper middle class status and, consequently, their wealth. All in all, the language of the many personalities portrayed in Great Expectations is indicative not only of the tone and character of the novel but also of the writing style of the author. After all, Dickens, along with Shakespeare, is regarded as one of the most popular and best-loved novelists internationally (Schlicke, 1999:466), both of whose works have been translated into all major European languages.

Since the focus of this paper is on the study of dialect translation from English into Greek, it is worth examining the Greek translations of Charles Dickens' Great Expectations. To my knowledge, there are seven Greek translations of the novel in question and I have decided to select the latest on the Greek market, namely, the first in 2016 in its $10^{\text {th }}$ edition (first edition: 1998) and the second in 2017. In more detail, the first Greek translation (henceforth TT1) is by the Patakis publishing house, and in particular, it is the tenth edition published in October 2016. The name of the translator, which also features on the front cover, is Pavlina Pompoudi. She was born in Athens in 1948. She studied History and Archaeology in the School of Philosophy at the University of Athens and also attended lectures in the Departments of Physics and Mathematics, in the Athens School of Fine Arts as well as the Byam Shaw School of Art in London. She is a poet, painter, writer and translator who has also written books for children. She has published two of her collections of poems, a novel and forty books for children. She has also translated into Greek twenty-six works of very famous authors such as Charles Dickens, T.S. Eliot, A. Chekhov etc. Finally, she is a member of the Greek Society of Authors.

The second Greek translation (henceforth TT2) is by the Minoas publishing house, and notably, is the first edition published in February 2017. The name of the translator, which is not shown on the front cover, is Thanasis Zavalos. $\mathrm{He}$ is an English teacher and a literary critic. He has translated into Greek twenty-six works of famous authors such as Charles Dickens, Paul Theroux, Ruth Ozeki etc. Incidentally, Ruth Ozeki's novel A Tale for the Time Being has been nominated for the Athens Prize for Literature.

\section{Translating Dialect: Problems and Solutions}

Having provided some background information with regard to the ST and the TTs, I will now focus on the issue of dialect translation since this is the pertinent subject of the present research. In particular, Great Expectations is very rich in dialogue, depicting in quite a vivid way the social class system in Victorian England. Describing a wide range of characters originating from different social classes, from criminals to respectable members of society, Dickens' sole purpose is to acquaint his readers with his characters and the way they speak. Page (1973:51) observes that apart from presenting the plot or describing the setting, one of the primary functions of dialect in 
literature is to introduce the characters and portray their development throughout the novel. This presents any would-be translator with a formidable task, since researchers have struggled to find a solution to the "twin problem of literary dialect and sociolinguistic representation in fiction" (Edney, 2011). In fact, Susan Ferguson (1998) has coined the term ficto-linguistics to draw attention to the fact that embedded in Victorian novels are self-contained systems in which:

speech relates in style as well as content to the speech of other characters, [and] all quoted language in a novel is contained within and potentially interacts with the language of the narrator.

(cited in Sönmez, 2014:637)

Hence, by highlighting and perhaps exaggerating to a lesser or greater extent the dialect spoken by his characters, Dickens manages not only to give them a distinct voice but also to indicate to the reader, their intellectual and financial standing in society.

In more detail, in Dickens' Great Expectations there are a number of characters, such as Abel Magwitch and Joe Gargery, whose dialect is represented by the use of non-standard grammar and orthography. And this is what makes the task of translators particularly challenging, since tackling dialect translation is not the easiest task for translators. Furthermore, the problematic relationship between sound and orthographic representation in the English language as well as the lack of exact counterparts of ST regional dialects in the TT, make the task of translators even more burdensome. In an effort to deal with such translation problems, a number of researchers have dealt with the issue of dialect translation (Berezowski, 1997; Kolb, 1998; Rozhin, 2001; Morini, 2006; De Martino Cappuccio, 2010; Rissmann, 2013; Li, 2014). Since the purpose of this paper is not to provide an exhaustive account of all the dialect-translation models that have been proposed up until now, but rather to highlight their general methods of approach, it will only be stated here that the dialect-translation strategies that have been proposed so far, amount to three. The first two are a) standardisation, where the ST dialect is translated with a TT standard and b) translation into dialect, which can be further subdivided into 1) the translation of the ST dialect, with one or two variants of the TT and 2) the translation of a ST variant by a non-standard TL variant. The third and final strategy involves the translation of the SL dialect into TT artificial language which implies the creation of an entirely fictitious dialect through the mixture of elements of different dialects. Of course, each strategy comes with its own perils, since standardising culture-bound items so as to make them fit the target culture might imply a cultural and social loss of meaning whereas overemphasising the regional element of the ST might produce an unnatural result or create non-existent sociocultural milieus. As Hatim and Mason (1990) insightfully observe:

Rendering ST dialect by TL standard has the disadvantage of losing the special effect intended in the ST, while rendering dialect by dialect runs the risk of creating unintended effects.

(Hatim and Mason, 1990:41)

Hence, there is no assumed superiority of one strategy over another since the translator might as well employ different dialect-translation strategies according to the occasion. After all, as Levý (1963:31) notes, translators are bound to their own culture and time and, inevitably, their translations are time and culture-dependent. Finally, it is worth pointing out that most of the scientific articles dealing with the issue of dialect translation are theoretical in nature and quite general, not differentiating between text types and genres. Rissmann (2013:30) is careful to note this deficiency and tries to shed light on this thorny issue by dealing with drama texts and their translations in German-speaking Europe. Irrespective of the text-type addressed or the dialect-translation strategy employed by each translator, every interpretation of the ST represents an effort to transmit not only the cultural elements of the play but also to capture the complexity of its characters.

\section{Research Architecture}

Through the combination of both quantitative and qualitative approaches, the primary aim of this study is to examine the norms present in the two Greek translations of Great Expectations so as to provide an in-depth analysis of the translators' behaviour as well as possible reasons governing such behaviour. In particular, Gideon Toury's norms offer a multi-dimensional framework that enable us to explore both the translation activity and product. In fact, the Greek translations of Great Expectations offer quite a fertile area of research since, to my knowledge, there is no study to date that has investigated the norms in the English-Greek dialect translation of Great Expectations. Thus, it is worthwhile doing a comparative study of two Greek translations of Great Expectations with respect to dialect translation. 
The dialect-translation model that will be employed for the present analysis is the one offered by Morini (2006), who in dealing with internal differences in translation, has suggested the following strategies that the translator might employ:

Whenever two or more variants of the same language inhabit the same textual place, the translator can: 1) write his target text in the standard version of the target language; 2) employ two or more variants of the target language; 3 ) translate one of the variants by a non-standard (incorrect, popular) variant of the target language.

(Morini, 2006:129)

He also adds a fourth possibility, that of creating a synthetic target language comprising modified words or phrases and "regional words and expressions phonetically adapted to the rules of the target language" (cited in Brett, 2009:51).

I will now look specifically at how dialect is translated in Great Expectations, but due, to constraints on space as well as a need to provide an in-depth analysis of a character's dialect, only the speech of Abel Magwitch will be examined here. More specifically, twenty instances of dialect translation will be explored. The first eleven examples are taken from the first chapter, where, the character of Abel Magwitch makes his appearance, whereas the rest are taken from chapter 42, which is almost completely narrated by Abel Magwitch. These two chapters were chosen because they allow us to establish the basic features of his dialect and provide us with the necessary data so as to uncover the characteristic dialect of Magwitch's language. Lastly, it should be mentioned that the dialect words and phrases of the ST that have been chosen for discussion are in bold whereas their translations appear in italics.

\section{Data Analysis}

Since the focus of this study is on the translation patterns of Magwitch's dialect, it is worth describing who he is and how his story unfolds throughout the novel, thus making him one of the leading characters. It could be argued that Magwitch is portrayed as a two-dimensional figure in the novel. In the beginning (see chapter 1) he is a rough convict whose crimes are too heinous to mention, but later (see chapter 42) he is shown to have a softer side as he is approaching death, thus showing that he has found peace and has come to terms with what life has given him. Like Joe, he views himself as a surrogate father of Pip, he loves him and supports him financially. His consistent and authentic dialogue is what singles him out as a memorable character for both the narrator and the reader alike and, more importantly, this is what defines him from both an educational and social standpoint. Some of his most characteristic dialogue patterns, which are going to be examined from a translation perspective, are outlined below:

\section{Example1}

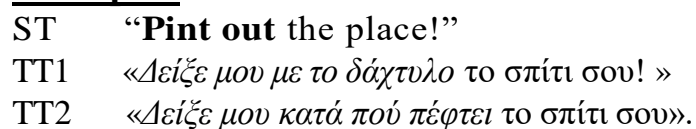

As Sönmez (2014:643) observes, the use of the word pint for point is one of the many localised dialect forms that can be found in Kent and Essex dialect glossaries and are shared by Joe and Magwitch. The diphthong /oi/ presents anomalies because $/ \mathrm{o} /$ is omitted. In this example the translator of TT1 uses a colloquial expression for the

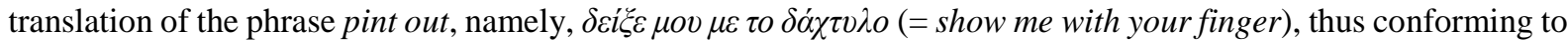
TL spoken norms. The same could be argued for the translator of TT2 who also uses a standard spoken expression

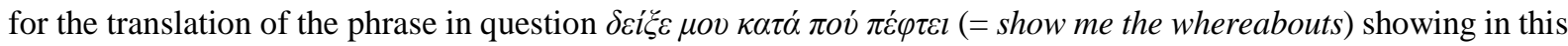
way his intention to preserve the colloquial style in the TT.

\section{Example 2}

ST "You young dog, said the man, licking his lips, what fat cheeks you ha' got."

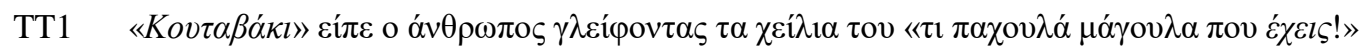

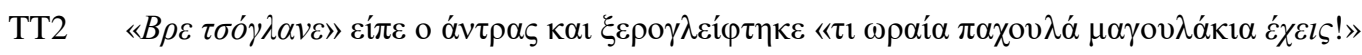

In this example, the contracted form $h a^{\prime}$ got has been translated in both TT1 and TT2 with the standard word $\dot{\varepsilon} \chi \varepsilon ı$ (= have got), which indicates the translators' efforts to conform with the norms of the written TL. It is also worth noting that the colloquial expression you young dog has been rendered in the TT1 with a word for word translation,

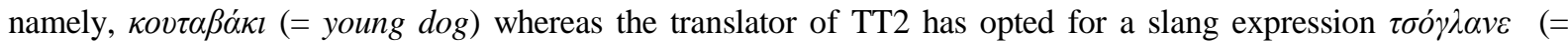
scumbag), thus giving a more vivid tone to the TT by adhering to the TL spoken expression norms. 


\section{Example 3}

ST "Darn Me if I couldn't eat 'em... and if I han't half a mind to't."

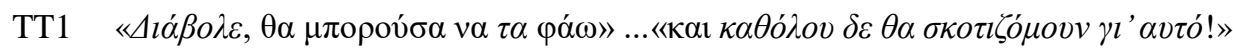

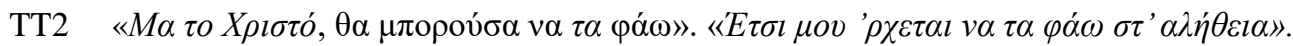

Magwitch's use of localised dialect forms is also evident in Example 3, where damn becomes darn, them is contracted to 'em, haven't to han't and it to 't. None of the deviant grammatical forms are retained in either of the two TTs. Instead, 'em is rendered into TT1 and TT2 with the personal pronoun $\tau \alpha(=$ them $)$ and the expression

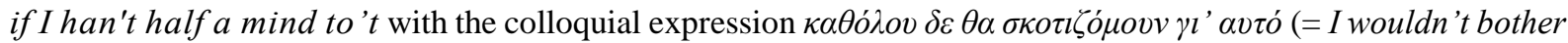

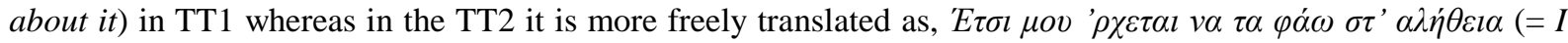
really want to eat them). In the TT1 the word darn is translated with its semantic equivalent, namely, $\delta i \alpha \dot{\beta} \beta{ }^{2} \varepsilon(=$

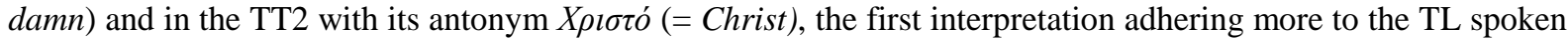
conventions while the second adhering to the TL written conventions.

\section{Example 4}
ST "Now lookee here!"

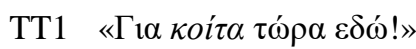

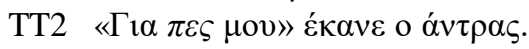

In this example, the addition of double /ee/ in the word look is not transferred in either of the TTs but instead in TT1 the standard written form $\kappa o i \tau \alpha ~(=l o o k)$ is preferred whereas the translator of the TT2 opts for the word $\pi \varepsilon \varsigma$ $(=t e l l)$, thus complying to the written conventions of the Greek target language.

\section{Example 5}

ST "And is that your father alonger your mother?"

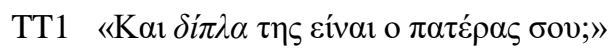

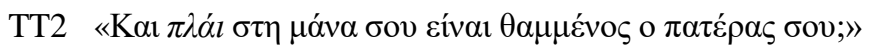

Similarly, the deviant dialect form alonger where there is an addition of /er/ is not transferred in the TTs and the standard written form $\delta i \pi \lambda \alpha(=n e x t)$ and $\pi \lambda \dot{\alpha} l$ (= besides) are preferred in TT1 and TT2 respectively.

\section{Example 6}

ST “Who d'ye live with - supposin' you're kindly let to live, which I han't made up my mind about?"

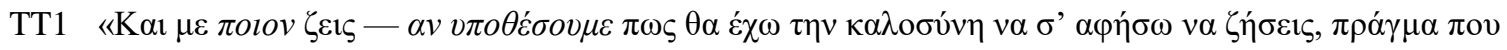

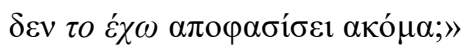

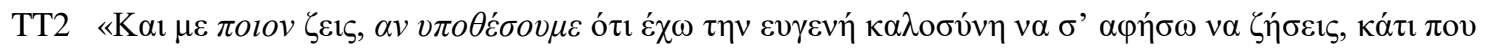

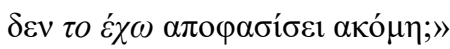

Example 6 is very rich in local dialect forms that are more often than not used by Magwitch. Would is contracted to $d$, you becomes ye, supposing loses its final letter $g$ and haven't becomes han't. None of these grammatically deviant forms are retained in TT 1 and TT2 where standard language is preferred instead. In more detail, the phrase, who d'ye live with is rendered in both TTs with the standard phrase $\kappa \alpha l$

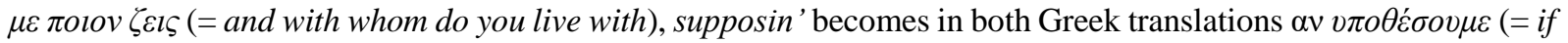

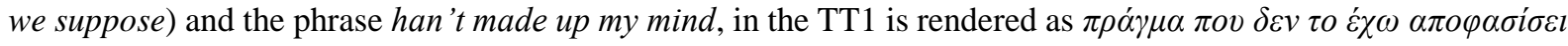

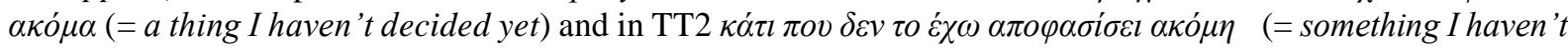
decided yet).

\section{Example 7}

ST “...never dare to say a word or dare to make a sign concerning your having seen such a person as me, or any person sumever..."

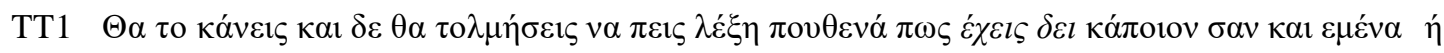

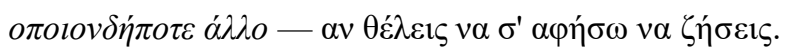

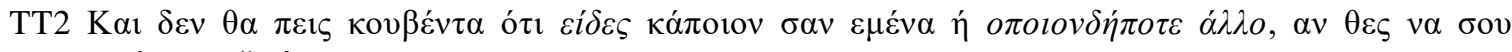
$\chi \alpha \rho i ́ \sigma \omega \tau \eta \zeta \omega \eta ́$.

In Example 7 the unusual past tense structure is of sufficient interest since Magwitch adds an $/ \mathrm{r} /$ to the 
word you, thus turning it into your. In this instance dialect is not reproduced in either of the two target texts where the standardised forms ć $\chi \varepsilon l \varsigma \delta \varepsilon l$ (= you have seen) and $\varepsilon i \delta \varepsilon \varsigma(=$ saw) are used. The word sumever, reminds us of language reminiscent of the courtroom and could be claimed to be used instead of the word whomsoever. Again, both TT translators opt for the standard written form

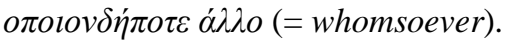

\section{Example 8}

ST You fail, or you go from my words in any partickler, no matter how small it is, and your heart and your liver shall be tore out, roasted and ate.

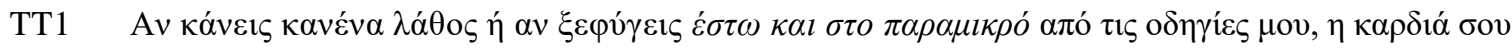

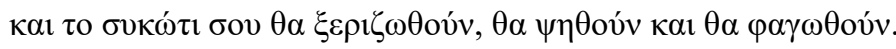

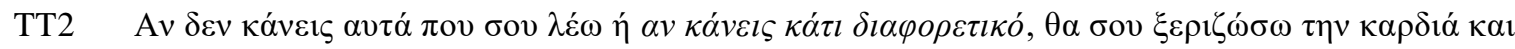

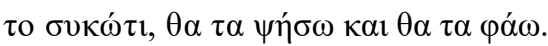

Similarly in Example 8, the deviant word partickler, which is used instead of the word particular is

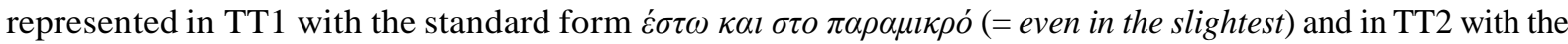

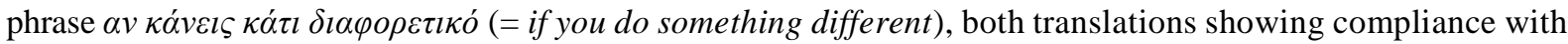
the TT written norms.

\section{Example 9}

ST "That young man has a secret way pecooliar to himself of getting at a boy..."

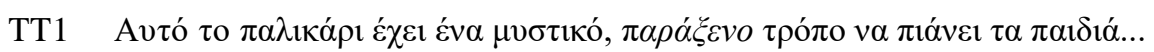

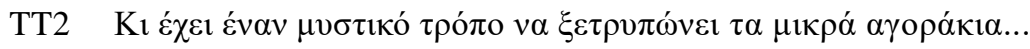

An idiosyncratic feature of Magwitch's uneducated speech, which could be argued to have a comic effect as well, is seen in his use of the word pecooliar where /u/ is turned into /oo/. This comic effect is not maintained in either of the two target texts where the standard word $\pi \alpha \rho \dot{\alpha} \xi \varepsilon v o$ (= peculiar) is preferred in TT1, suggesting the promotion of standard written language in the specific TL context. It is worth noting that the translator of TT2 has omitted translating the word in question.

\section{Example 10}

ST It is in wain for a boy to attempt to hide himself from that young man.

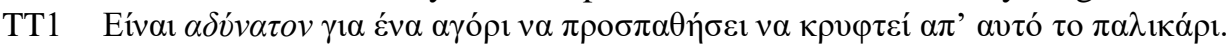

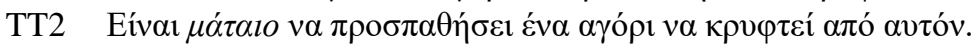

One of the most popular dialect forms found in both Essex and Kent dialect glossaries is the substitution of $w$ for $v$ and vice versa. In this example, the word vain becomes wain. This feature of dialect does not exist in

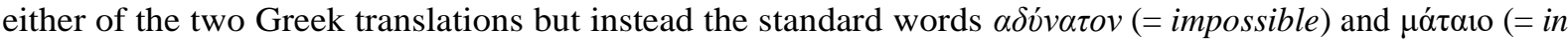
vain) are used indicating a clear preference for the standard version of the target language.

\section{Example 11}

ST I am a-keeping that young man from harming of you at the present moment with great difficulty.

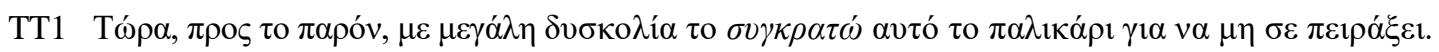

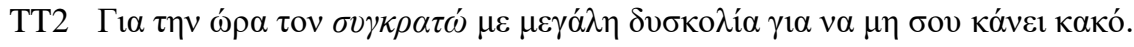

In this example, there is an addition of /a/ in the word keeping, another characteristic of Magwitch's idiosyncratic dialect which is not maintained in the target texts, where both translators opt for the standard word $\sigma 0 \gamma \kappa \rho \alpha \tau \dot{\omega}$ (= keep him away from, restrain).

\section{Example 12}

ST Summun had run away from me - a man - a tinker - and he'd took the fire with him, and left me wery cold.

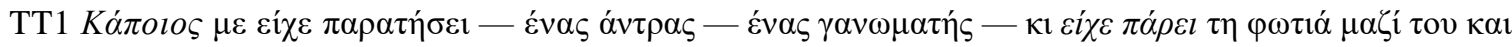

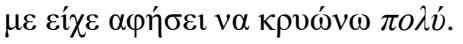

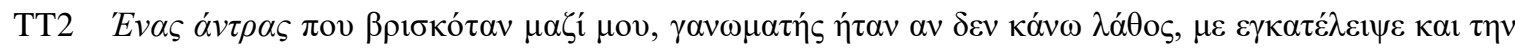

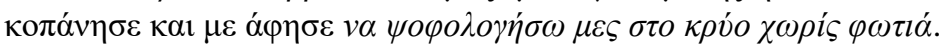


Example 12 is very rich in idiosyncratic dialect forms from its very beginning. The word someone is turned into summun, the past perfect participle taken becomes took and $/ \mathrm{v} /$ is substituted with $/ \mathrm{w} /$ in the word very. Again, all these non-standard dialect forms seem to evaporate in the two target texts under analysis. In a more analytic

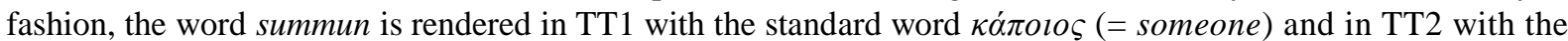

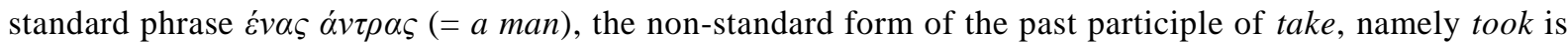

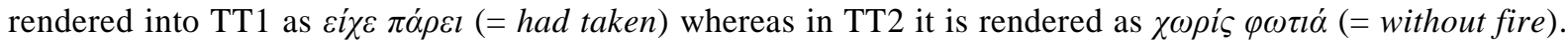
Lastly, the word wery is transferred into TT1 with the standard word $\pi 0 \lambda \dot{v}(=v e r y$ ) whereas in TT2 it becomes $\mu \varepsilon \varsigma \sigma \tau o$ крv́o (= inside the cold). Magwitch's characteristic dialect seems to disappear in both target texts.

\section{Example 13}

ST I know'd my name to be Magwitch, chrisen'd Abel.

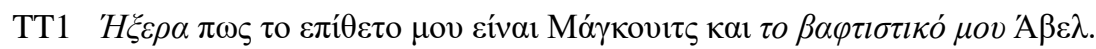

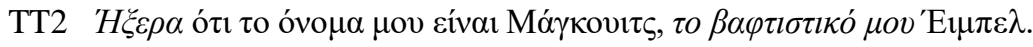

Example 13 is also indicative of Magwitch's use of non-standard forms of past tense (Sönmez, 2014:643). The past tense of the verb know, namely, knew has become knowed in its contracted version know'd, and the past tense of christen, that is, christened has been turned into chrisen'd. None of these grammatical anomalies are evident in TT1 and TT2 where know'd is translated with the standard Greek past tense $\dot{\eta} \xi \varepsilon \rho \alpha$ (=I knew) and chrisen' $d$ with

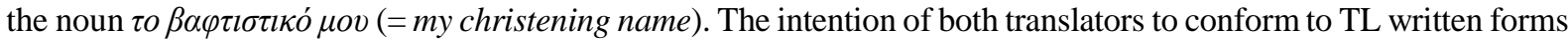
is evident.

\section{Example 14}

ST Then they looked at me, and I looked at them, and they measure my head', some on 'em - they had better a measured my stomach - and others on 'em giv me tracts what I couldn't read, and made me speeches what I couldn't unnerstand.

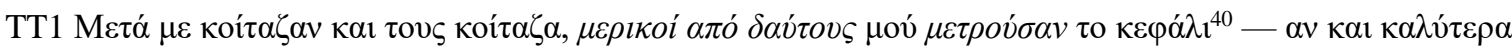

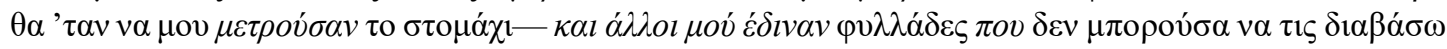

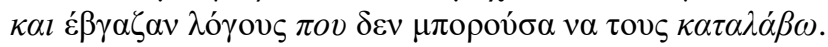

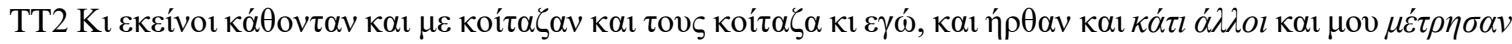

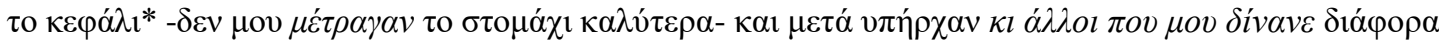

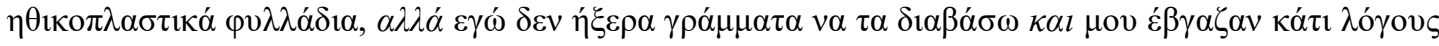

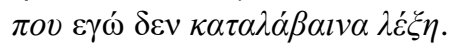

In Example 14, one can notice various examples of dialect variation. The word measure is meant to be in the past tense, that is measured, them has become 'em, where there is elision of the interdental fricative $/ \delta /$, there is an additional /a/ before the word measured, on is meant to be of, the second them has become again 'em, that has been turned into what and understand into unnerstand. Give also loses an $e$ at the end. As was the case in the previous example, none of the aforementioned dialect forms are maintained in the two Greek target texts. More

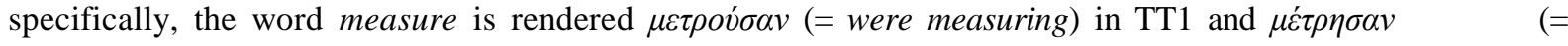

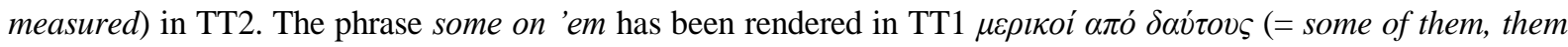

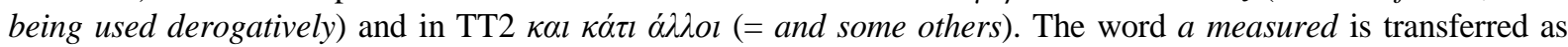
$\mu \varepsilon \tau \rho o v ́ \sigma \alpha v$ (= measured) in TT1 and $\mu \varepsilon \dot{\tau} \tau \rho \alpha \gamma \alpha v$ (= were measuring) in TT2 and the phrase couldn't unnerstand as $\delta \varepsilon v$

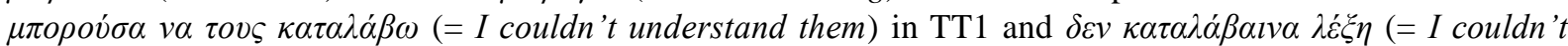
understand a single word) in TT2. Lastly, the first what meaning that is rendered into TT1 as $\pi \circ 0$ (= that) and into TT2 as $\alpha \lambda \lambda \dot{\alpha}(=b u t)$ whereas the second what is translated in both target texts as $\pi o v$ (= that). Again, the translators' attempt to conform to TL written expression norms is evident.

\section{Example 15}

ST They always went on agen me about the Devil.

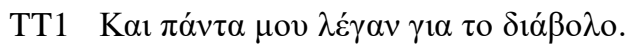

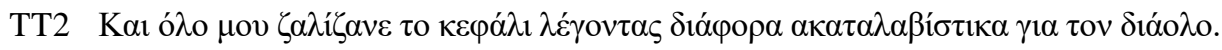

Example 15 is a characteristic example of eye-dialect. George P. Krapp was the first to coin such a term in The English Language in America in 1925 (Mc Arthur 1998, cited in Brett, 2009:49). In simple words, the term refers to unconventional spelling that offends the eyes and not the ears. As Sönmez (2014:642) observes, eyedialect refers to "non-standard spellings which do not indicate any non-standard pronunciation", meaning that these misspellings are actually respellings of standard pronunciation e.g. peepul for "people". Later, the term acquired a broader meaning, incorporating "any variation of spelling to indicate particular pronunciations or 
accents" (cited in Brett, 2009:49). In this case, the word again is spelled as agen and the dipthong /ai/ is turned into /e/. In both TTs, the translators have omitted translating the word in question, focusing on the phrase went $o n$. Finally, it is worth noting the syntactic abnormality of this sentence since after the adverb agen, there is the addition of the personal pronoun $m e$.

\section{Example 16}

ST Howsomever, I'm a getting low, and I know what's due. Dear boy and Pip's comrade, don't you be afeerd of me being low.

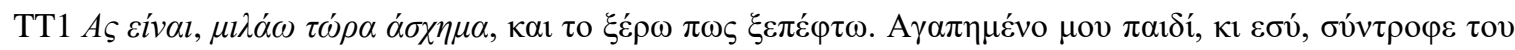
$\Pi i \pi, \mu \eta \varphi о \beta o ́ \sigma \alpha \sigma \tau \varepsilon \pi \omega \varsigma, \alpha \varphi \varphi \varepsilon \rho \theta \dot{\alpha} \alpha \chi \eta \mu \alpha$.

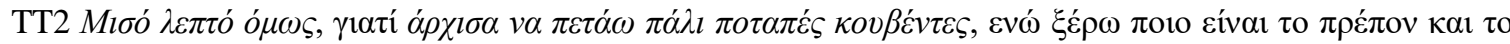

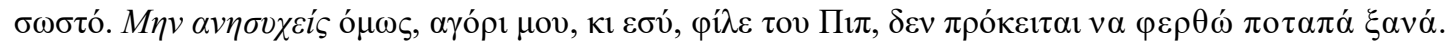

In this example, three instances of dialect are worth discussing. The first one is the word howsomever which is substituted for the word however, the second is the addition of /a/ before the word getting and the third, and most interesting, is the word afeerd which is used instead of the word afraid. As Sönmez (2014:643) observes, the word afeerd, being one of the first words found in Kent and Essex glossaries, was spoken by people all over England, indicating that it was one of the most frequent examples of non-standard speech. In both TTs, it is translated conventionally, that is, in TT1 the word $\varphi о \beta \delta \sigma \alpha \sigma \tau \varepsilon$ (= you are afraid) is employed whereas in TT2 a

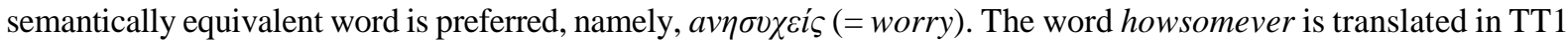

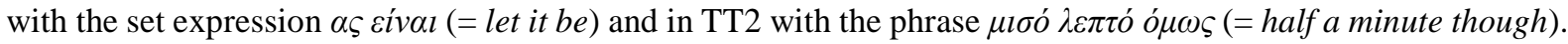

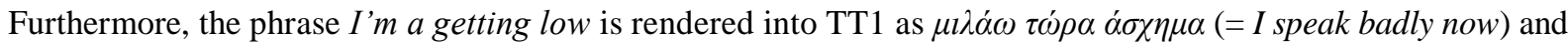

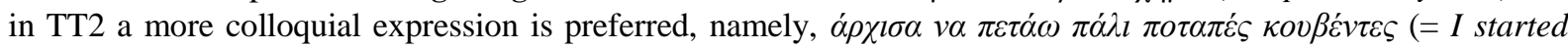
throwing nasty words again). No sign of adhering to dialect can be seen in the target texts in question.

\section{Example 17}

ST At Epsom races, a matter of over twenty years ago, I got acquainted wi' a man whose skull I'd crack wi' this poker, like the claw of a lobster, if I'd got it on this hob.

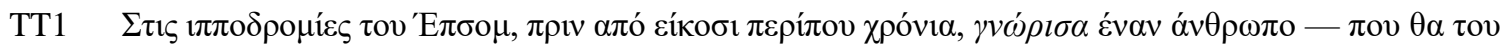

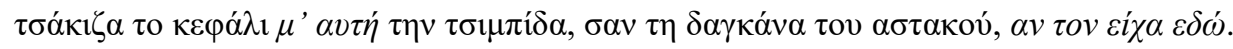

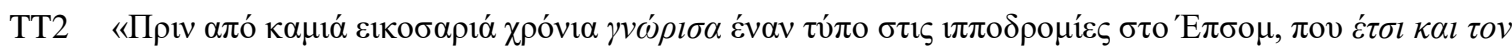

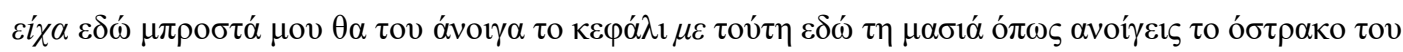

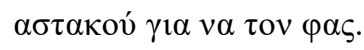

In Example 17, there is elision of the interdental fricative $/ \delta /$ in both instances of the word with, which has been turned into $w i$ '. Also worthy of attention is the incorrect use of the phrase if I'd got, which in its full form, I think stands for if I had got. Therefore, the verb 'have got' has been incorrectly used as a past tense ('had got') instead of the verb 'have' as a past tense. This being the case, it should have been 'if I had'. Standardisation rather than translation of dialect is the preferred norm in both Greek target texts since the phrase got acquainted wi' is translated in both TTs with the word $\gamma v \omega^{\prime} \rho l \sigma \alpha(=I m e t)$, the second wi' in TT1 with the word $\mu^{\prime}$ (= with, in its contracted form because of a vowel following) and in TT2 with the word $\mu \varepsilon(=$ with $)$ in its full form. In a similar fashion, the phrase

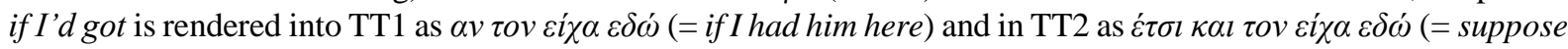
I had him here).

\section{Example 18}

ST The time wi' Compeyson was a'most as hard a time as ever I had; that said, all's said.

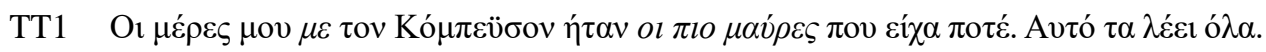

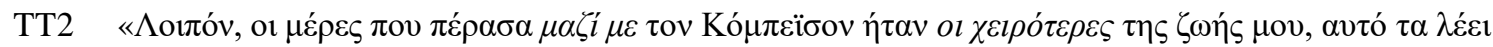
ó $\lambda \alpha$.

Example 18 has three instances worthy of attention. The first one is the elision of the interdental fricative $/ \delta /$ in the word with, the second is the elision of $/ 1 /$ in the word almost and the third is the addition of $a$ in front of the word time. Conventionality is the preferred pattern in the Greek target translations, since wi' is translated in TT1 as $\mu \varepsilon(=$ with $)$ and in TT2 as $\mu \alpha \zeta i \mu \varepsilon$ (= together with). Similarly, the expression $a^{\prime}$ 'most as hard is rendered in TT1 as

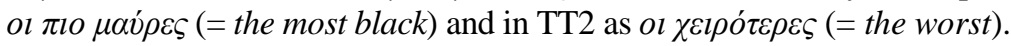




\section{Example 19}

ST And when it come to character, warn't it Compeyson as had been to the school, and warn't it his schoolfellows as was in this position and in that, and warn't it him as had been know'd by witnesses in such clubs and societies, and nowt to his disadvantage?

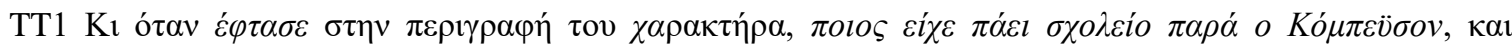

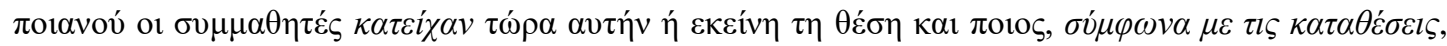

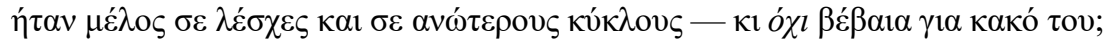

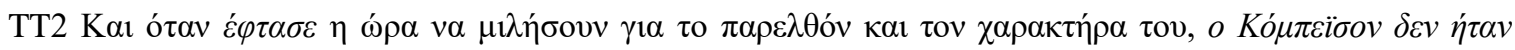

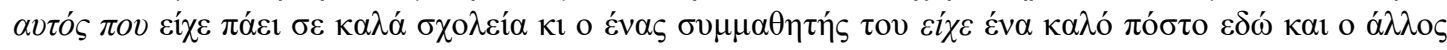

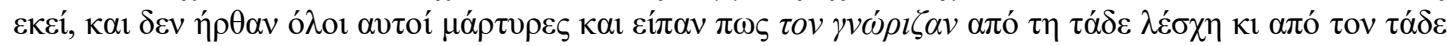

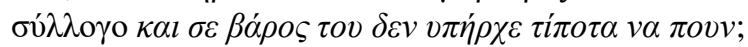

Example 19, full of examples of dialect, is typical of Magwitch's speech style. The word come should have been comes, wasn't has been turned into warn't, known has been turned into know'd and not into nowt. Finally the phrase was in this position should have been were in his position. Of particular syntactic interest is the incorrect use of the word as for the word who. None of the previously-mentioned grammatical or syntactical anomalies are maintained in the Greek target texts where the conventional forms are given precedence. The word come is rendered into both TTs with the standard written word $\varepsilon \dot{\varphi} \tau \alpha \sigma \varepsilon$ (= came), warn't is transferred in TT1 with a

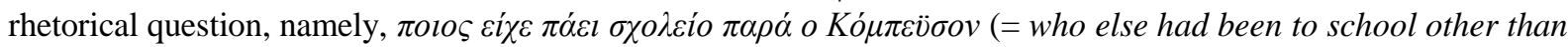

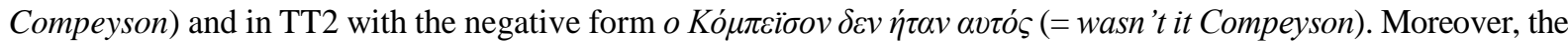

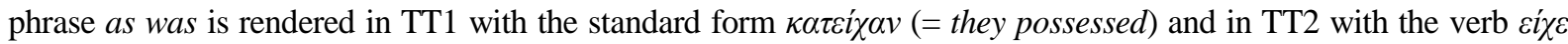
(=had). The phrase had been know'd has been rendered in TT1 with the expression $\sigma \dot{0} \mu \varphi \omega v \alpha \mu \varepsilon \tau \iota \varsigma \kappa \alpha \tau \alpha \theta \varepsilon \dot{\sigma \varepsilon l \varsigma}(=$ according to the testimonies) which shows a freer translation, whereas the translator of the second target text

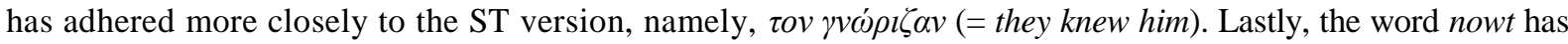
been translated with the conventional Greek word $\chi^{\prime}(=n o t)$ in TT1 whereas in TT2, the translator has opted for a

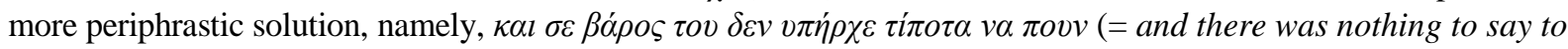
his disadvantage). Again, compliance with the TL norms of written conventions seems to be of utmost importance for both translators of the two target texts in question.

\section{Example 20}

ST "Once out of this court, I'll smash that face of yourn!" ain't it Compeyson as prays the Judge to be protected, and gets two turnkeys stood betwixt us?

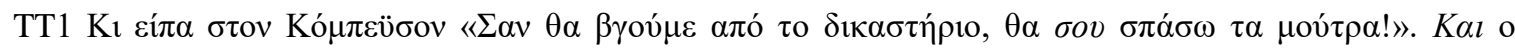

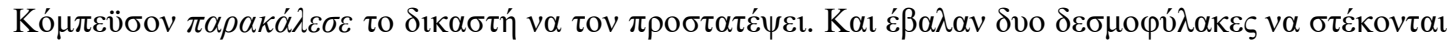
$\alpha v \alpha \dot{\alpha} \mu \varepsilon \sigma \alpha \mu \alpha \varsigma$.

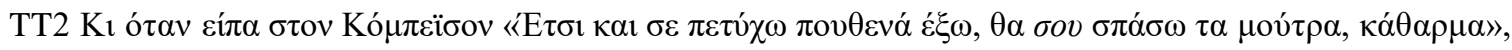

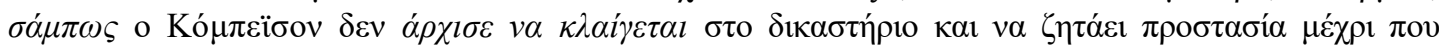

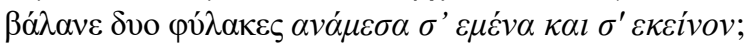

The first thing that one notices in Example 20 is the use of yourn for yours, a frequently used word in both Kent and Essex dialect dictionaries (Sönmez, 2014:644). As expected, it is rendered into both TTs with the possessive pronoun $\sigma o v$ (= yours). Similarly, the informal eye-dialect word ain 't is translated in TT1 with the standard word $\kappa \alpha l$ (= and $)$ and in TT2 with the word $\sigma \alpha \dot{\alpha} \mu \pi \omega \varsigma$ (= possibly). Syntactically speaking, the word as is used instead of who and betwixt instead of between. In both TTs, the conventional forms are clearly preferred with as prays being translated in TT1 as $\pi \alpha \rho \alpha \kappa \alpha \dot{\lambda} \varepsilon \varepsilon \sigma \varepsilon$ (= begged) and in TT2 as $\alpha \rho \chi l \sigma \varepsilon v \alpha \kappa \lambda \alpha i \gamma \varepsilon \tau \alpha l$ (= began feeling sorry for himself) and betwixt being rendered into both target texts as $\alpha v \alpha \dot{\mu \varepsilon \sigma \sigma \alpha}(=$ between). It seems to be the case, that these particular translators are not willing to go the extra mile in trying to capture the unique Dickensian flavour of Magwitch's dialect. Possible reasons behind such a preference are outlined in the next section.

\section{Where Did All the Dialect Go? Standardisation in Dialect Translation}

The use of dialect in Charles Dickens' Great Expectations is meant to do much more than add a comic element and colour to the novel. The use of dialect also has a strong symbolic meaning and aims at giving an authentic voice to the characters in question. Through the use of dialect Magwitch is portrayed as a social outcast who has a marginalised social position, belonging as he does, to a lower social class. Hence, the use of dialect reveals the intention of the author to convey a specific cultural message and its elimination inevitably affects how Magwitch is portrayed, since his register is changed in the target text. As De Martino Cappuccio (2010:108) puts it "any manipulation of the text which weakens such a characteristic inevitably reduces the cultural impact of the play as 
well". However, Rissmann (2013:224) argues that in German-speaking Europe there are only a few translated plays in the theatre that employ dialect translation. In other words, there are other, perhaps more important, factors that determine the translation policy adopted, that being, standardisation or use of dialect. She goes on to argue (2013:225) that there are political and national factors dictating translation choices, such as the association of national identity with a specific linguistic variation and the use of dialect in specific drama movements.

On closer inspection of the two Greek translations of Charles Dickens' Great Expectations, one can see that standardisation is the norm in the majority of the examples discussed. The translators could have used examples of non-standard spelling and grammar more frequently, or they could have assigned different Greek dialects to the prominent characters in the novel. It is evident that the translator of TT1, namely, Pavlina Pampoudi, prefers words and structures that adhere more closely to TL written conventions whereas Thanasis Zavalos makes use of more

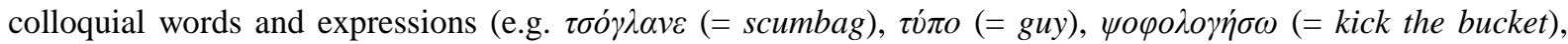

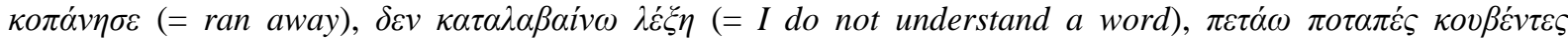
(= throw nasty words). In this respect, Pavlina Pampoudi adheres more closely to the first strategy of dialect translation suggested by Morini (2006:129), namely, she employs the standard version of the target language, whereas Thanasis Zavalos' target text could be claimed to occasionally make use of more colloquial target language words, thus favouring Morini's (2006) second strategy.

The question that immediately comes to mind is the following: Would the preservation of dialect in the TT be of any good? And for whom? For the readers, for the publishing house? My opinion is that it would have sounded odd to replace this Dickensian dialect with a Greek one, given that the audience knows that this novel was set in nineteenth century England. Furthermore, employing one particular Greek dialect instead of another would significantly restrict the number of people who would be able to read such a novel. This societal factor mitigates against the use of dialect translation but there are more important factors that influence whether or not a dialect translation is used.

More specifically, the commissioning practices of publishers greatly influence the translation-strategies employed in novels. Established publishing houses, such as Patakis, usually employ professional translators and promote standardisation strategies. Being a profit-making business, each established publishing house wants to make sure that the novel's translation is read by a great number of people. The choice of a particular Greek dialect would limit the number of people who would be able to sit back and enjoy reading such a novel and would inevitably limit the possible profits of the publishing house. That being the case, culture-specific terms, local or regional dialects should be avoided at all costs. In other words, the translation norm promoted by both Greek publishers is that of standardisation. Hence, as Rissmann (2013:231) points out "the use of dialect in ST plays only a minor role in the decision to translate them into dialect".

Since there is no major political/national motivation behind these Greek translations, standardisation seems to be the preferred dialect translation strategy employed to a large extent. Standardisation permits the elevation of register and ensures a smooth, standard language that can be understood by a great number of people. Perhaps, conforming to publishers' demands, and consequently, to readers' expectations is the main priority in the translation business. The target literary market has the first and last word in deciding which dialect-translation strategy is mostly accepted. Moreover, maybe standardisation with the addition of "he/she said in a light/heavy/musical etc. dialect" could sometimes be used if no other solution can be found. Lastly, if we were dealing with a different genre, such as drama translation, the commissioning and distribution practices of drama translations in Greece might have been different.

\section{Conclusion: Great Expectations...Great Translations?}

In this study, an attempt was made to provide an insight into the complexities of dialect translation in two Greek translations of Charles Dickens' Great Expectations. Utilising the paradigm of Descriptive Translation Studies, this paper has attempted to discover and discuss important factors that influence the translation norms of English novels into Greek. Nevertheless, its scope is limited since only one Dickensian novel was explored and only two of its Greek translations. There is still a need to undertake comparative studies of norms in dialect translation across Dickens novels as well as comparative studies of the work of individual translators (Li, 2014:326). Moreover, more thorough and systematic research on dialect use in novel and in other genres could shed some light on the status of both TTs and translators. For that, of course, to happen there must be continuous and fertile dialogue between translation scholars and practitioners (Rissmann, 2013:231). Thus, to characterise a translation as great or not so great, or successful or not so successful is futile and dangerous. There are no good or bad translations but multiple renditions of meaning, each worthy of study and attention. 


\section{References}

Baker, M. (ed.) (1998). Routledge Encyclopedia of Translation Studies. London and New York: Routledge. https://doi.org/10.4324/9780203359792

Berezowski, L. (1997). Dialect in Translation. Wydawnictwo Uniwersytetu Wroclawskiego: Acta Universitatis Wratislaviensis.

Brett, D. (2009). Eye-Dialect: Translating the Untranslatable. AnnalSS, 6, 49-62.

De Martino Cappuccio, A. (2010). Translation of Dialect and Cultural Transfer: an Analysis of Eduardo De Filippo's Theatre. Doctoral Dissertation. Coventry: University of Warwick, UK.

Dickens, C. (1965). Great Expectations. London: The Penguin English Library. https://doi.org/10.1007/978-1-349-81691-0

Edney, S. (2011). Recent studies in Victorian English literary dialect and its linguistic connections. Literature Compass, 8(9), 660-674. https://doi.org/10.1111/j.1741-4113.2011.00831.x

Even-Zohar, I. (1978/2000). The position of translated literature within the literary polysystem. In L. Venuti, (Ed.) (2000), The Translation Studies Reader (pp. 192-197). London and New York: Routledge,

Even-Zohar, I. (1990). Polysystem Studies. Tel Aviv: The Porter Institute of Poetics and Semiotics. Durham, NC: Duke University Press, special issue of Poetics Today, 11(1).

Ferguson, S. (1998). Drawing fictional lines in the Victorian novel. Style, 32(1), 1-17.

Gentzler, E. (2001). Contemporary Translation Theories. Clevedon: Multilingual Matters.

Hermans, T. (1995). Revisiting the classics: Toury's empiricism version one. The Translator, 1(2), 215-223. https://doi.org/10.1080/13556509.1995.10798958

Kolb, W. (1998). Sprachvarietäten (Dialekt/Soziolekt) . In $\quad$ M. Snell-Hornby et al.(Eds.), Handbuch Translation (pp. 278-80).Tübingen: Stauffenburg.

Lefevere, A. (1983). Poetics (today) and translation studies. In D. Weissbort, (Ed.), Modern Poetry in Translation (pp. 190-195). London and Manchester: MPT and Carcanet.

Levý, J. (1963). The Art of Translation. Prague.

Li, M. (2014). Norms of Translating Fiction from English into Chinese (1979-2009): The Case of Charles Dickens' Great Expectations. Doctoral Dissertation. Salford: University of Salford, UK.

McArthur, T. (1998). Eye dialect. The Concise Oxford Companion to the English Language. Oxford: Oxford University Press.

Morini, M. (2006). Norms, difference and the translator: or, how to reproduce double difference. RiLUnE Review of Literatures of the European Union, 4, 123-140.

Page, N. (1973). Speech in the English Novel. London: Longman.

Pym, A. (2010). Translation theory today and tomorrow-responses to equivalence. In Lew N. Zybatow (Ed.), Translationswissenschaft - Stand und Perspektiven (pp.1-14). Frankfurt: Peter Lang.

Rissmann, J. (2013). Dialect, Drama and Translation: A Socio-cultural Investigation into the Factors Influencing the Choice of Strategies in German-Speaking Europe. Doctoral Dissertation. Coventry: University of Warwick, UK.

Rozhin, S., K. (2000). Translating the untranslatable: Edward Redlínski's cud no greenpoincie [Greenpoint miracle] in English. In C.A. Upton (Ed.), Moving Target: Theatre Translation and Cultural Relocation (pp.139-146). Manchester: St. Jerome.

Schlicke, P. (1999). Oxford Reader's Companion to Dickens. Oxford: Oxford University Press.

Shuttleworth, M. ( 1998). Polysystem theory. In M. Baker, (Ed.), Routledge Encyclopedia of Translation Studies (pp. 176-179). London and New York: Routledge.

Shuttleworth, M. and Cowie, M. (1997). Dictionary of Translation Studies. Manchester: St. Jerome.

Sönmez,M. (2014). Authenticity and non-standard speech in Great Expectations. Victorian Literature and Culture 42, 637-669. https://doi.org/10.1017/S1060150314000230

Toury, G. (1980). In Search of a Theory of Translation. Tel Aviv: The Porter Institute for Poetics and Semiotics. 
Toury, G. (1995). Descriptive Translation Studies and Beyond. Amsterdam and Philadelphia: John Benjamins. https://doi.org/10.1075/btl.4

\section{Copyrights}

Copyright for this article is retained by the author(s), with first publication rights granted to the journal.

This is an open-access article distributed under the terms and conditions of the Creative Commons Attribution license (http://creativecommons.org/licenses/by/4.0/). 